Article

\title{
Preparation and Evaluation of Epoxy Resin Prepared from the Liquefied Product of Cotton Stalk
}

\author{
Nuerjiamali Tuohedi (1) and Qingyue Wang *(1) \\ Graduate School of Science and Engineering, Saitama University, 255 Shimo-Okubo, Sakura-ku, \\ Saitama 338-8570, Japan; tuohedi.n.979@ms.saitama-u.ac.jp \\ * Correspondence: seiyo@mail.saitama-u.ac.jp; Tel.: +81-48-858-3733; Fax: +81-48-858-9197
}

Citation: Tuohedi, N.; Wang, Q. Preparation and Evaluation of Epoxy Resin Prepared from the Liquefied Product of Cotton Stalk. Processes 2021, 9, 1417. https://doi.org/ $10.3390 /$ pr9081417

Academic Editor: Paola Ammendola

Received: 29 June 2021

Accepted: 9 August 2021

Published: 16 August 2021

Publisher's Note: MDPI stays neutral with regard to jurisdictional claims in published maps and institutional affiliations.

Copyright: (c) 2021 by the authors. Licensee MDPI, Basel, Switzerland. This article is an open access article distributed under the terms and conditions of the Creative Commons Attribution (CC BY) license (https:// creativecommons.org/licenses/by/ $4.0 /)$.

\begin{abstract}
Liquefaction of waste lignocellulosic biomass is a viable technology for replacing fossil fuels and meeting sustainable development goals. In this study, bio-based epoxy resins were prepared from polyhydric-alcohol-liquefied cotton stalk by glycidyl etherification. The cotton stalk was liquefied in a polyethylene glycol/glycerol cosolvent under $\mathrm{H}_{2} \mathrm{SO}_{4}$ catalysis. Epon 828 and cotton-stalk-based epoxy resins could be cured using methylhexahydrophthalic anhydride as the curing agent, and the curing process was exothermic. The thermal properties and tensile strength of cured resins were investigated to examine the effect of adding cotton-stalk-based resin on the performance of the copolymerized epoxy resin. Further, the liquefied-cotton-stalk-based epoxy resin was blended with Epon 828 at different ratios (10, 20, and 30 mass\%) and cured with a curing agent in the presence of 2-methylimidazole catalyst. An increase in the peak temperature and a reduction in the heat of curing and activation energy of the Epon 828 epoxy resin was observed with increasing content of the cotton-stalk-based epoxy resin. The tensile strength (35.4 MPa) and elastic modulus (1.5 GPa) of the highly crosslinked cotton-stalk-based epoxy resin were equivalent to those of the petroleum-based epoxy resin Epon 828.
\end{abstract}

Keywords: liquefaction; hydroxyl number; cotton-stalk-based epoxy resin; curing thermal properties; tensile strength

\section{Introduction}

Biomass is a promising renewable resource, considering the climate change caused by petroleum consumption and the impending power crisis. Lignocellulosic biomass is a common term used for all plant-derived organic matter, including crops, forest products, marine products, and some organic wastes such as municipal solid waste and agricultural waste [1]. It represents an abundant renewable resource that can be used to produce energy [2] and valuable chemicals [3,4]. Agricultural wastes are abundant and widely available. If they are not disposed of or utilized appropriately, they are not only wasted but are also likely to cause serious environmental pollution. The rational utilization of agricultural waste resources is conducive to the harmonious development of human society as well as nature. It can not only decrease agricultural nonpoint source pollution but also improve rural environmental conditions, improve the quality of life of farmers, and promote sustainable agricultural development.

Among the various methods of processing biomass resources, liquefaction is a viable one. Typically, biomass liquefaction is accomplished by the solvolysis of waste lignocellulosic biomass. This process involves the cleavage of various chemical bonds in the biomass using an organic solvent. Different organic solvents such as polyhydric alcohols [5,6] phenol [7,8], ethylene carbonate [9,10], dioxane [11], ethanol [12], and acetone [13,14] have been used in wood liquefaction. The wood liquefaction technology essentially involves the chemical modification of wood by the esterification or etherification of the hydroxyl groups commonly found in the main components of wood, viz., high-molecular-weight cellulose, 
hemicellulose, and lignin. The liquefaction technology could effectively transform waste biomass into biodegradable resins and could thus solve the problem of waste biomass disposal and degradability of the resin.

In recent years, liquefaction studies have been mainly focused on the use of phenol and polyhydric alcohols as solvents. For instance, Kishi and Fujita liquefied wood using phenol as the solvent and prepared an epoxy resin using the obtained phenol resin as a raw material $[4,15]$. The liquefied bio-based epoxy resin exhibited excellent mechanical properties fiber-reinforced composite material with good adhesion to matrix resin. However, given environmental safety considerations, alcohols are better solvents than phenols for wood liquefaction. Currently, an epoxy resin derived from biomass has attracted much attention owing to the growing demand for materials derived from renewable resources. With an epoxy resin having good adhesion and mechanical properties, it is widely used in various fields, such as an adhesive [16], coatings [17], and the resin matrix composite [18,19].

Cotton is grown on a large scale in China and is the main crop in the Xinjiang Uygur Autonomous Region. Xinjiang Uygur Autonomous Region is a natural economic zone dominated by agriculture and animal husbandry, with abundant crops. At present, agricultural wastes are not fully utilized and are often burned for simple disposal, causing waste of resources and environmental pollution and causing health problems to the farmers and the public. With the background of economic development, a lot of energy and resources are being consumed. In addition, the increase in the use of fossil resources and the burndown of agricultural waste have aggravated ecological and environmental pollution problems $[20,21]$. Therefore, it is of great significance to study how to increase the added value of agricultural waste residues and to improve the utilization value of the entire biomass by improving the performance of environmentally friendly materials [22]. Moreover, our research group has successfully produced biopolyols and polyurethane foams from liquefied cotton stalk [5]. In the present study, we liquefied cotton stalk using a polyhydric alcohol as the liquefaction solvent, and then prepared bio-epoxy resins by polymerizing the liquefied product of the cotton stalk. The effects of the composition of the liquefaction mixture on the properties of the liquid products and epoxy resins were investigated. Further, factors that affect the liquefaction of cotton stalk, including the reaction time, temperature, and liquid ratio, were also analyzed. Finally, the liquefied product was used as the polyol component for preparing an epoxy resin by reacting it with diglyceryl ether of bisphenol A (Epon 828). In addition, the thermal properties of the resultant resins were studied by differential scanning calorimetry (DSC) and thermogravimetric analysis (TGA).

\section{Materials and Methods}

\subsection{Materials}

Cotton stalk, a waste lignocellulosic biomass, was collected from Toksun Farm, Xinjiang Province, China. All chemicals used in the liquefaction of this wood and the synthesis of cotton-stalk-based epoxy resins were purchased from commercial sources and used without further purification. Polyethylene glycol (PEG 400), glycerin, and all other chemicals used in the liquefaction of the cotton stalk, were of reagent grade and used without further purification. Epichlorohydrin, sodium hydroxide $(\mathrm{NaOH})$, tetrahydrofuran, methanol $(\mathrm{MeOH})$, and hydrochloric acid $(\mathrm{HCl})$ were supplied by from Wako Pure Chemical Co. Ltd., Osaka, Japan. Liquid diglycidylether of bisphenol A (Epon 828) as given in Scheme 1 with an epoxy equivalent weight of 185-192 eq. g was procured from Fuji Chemical Co. Ltd., Osaka, Japan. The resins were cured with a stoichiometric amount of polyamide amine (PAA; active hydrogen equivalent: 63 g/eq., Fuji Chemical Co. Ltd., Osaka, Japan). 


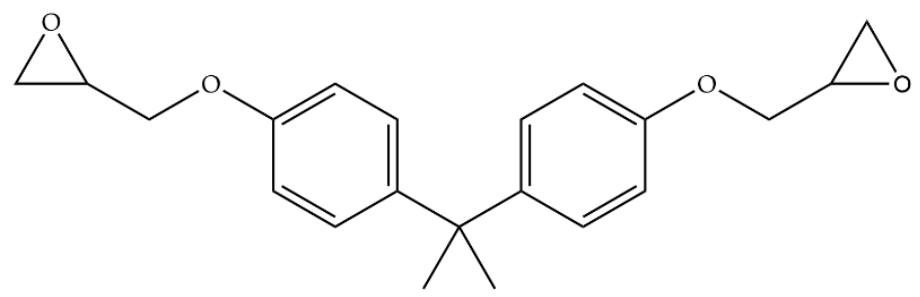

Scheme 1. Structure of liquid diglycidylether of bisphenol A (Epon 828).

\subsection{Preparation of Liquefied Cotton Stalk}

The cotton stalk was first dried using a thermal controller at $105^{\circ} \mathrm{C}$ for $12 \mathrm{~h}$. Then, the dried sample $(10 \mathrm{~g})$ was mixed with PEG 400 and glycerin used as the liquefaction reagents at different ratios in the range of $10 / 0$ to $6 / 4(w / w \%)$ in a $500 \mathrm{~mL}$ three-necked flask equipped with a stirrer and a reflux condenser $[5,23]$. The solvent/cotton-stalk ratio was varied in the range of $3 / 1$ to $5 / 1(w / w \%)$, while the catalyst concentration was varied in the range of $1-4(w / w \%)$. Then, it was reacted at different temperatures $\left(130-160{ }^{\circ} \mathrm{C}\right)$ for different times of $90 \mathrm{~min}$. Mechanism of cellulose degradation and decomposition during liquefied processes of woody materials shown in Scheme 2 [24,25]. Thereafter, a sample of the liquefied cotton stalk samples in the flask was collected in a vial, and the residues were analyzed. The reaction samples were collected in vials after specified durations and immediately soaked in cold water to terminate the reaction. Then, $20 \mathrm{~mL}$ of methanol was added to each collected sample, and the resulting sample was suction-filtered using a pump (EVP-1000, KNF, EYELA Co. Ltd., Tokyo, Japan) and PTFE filters (C5, Advavtec). Subsequently, the filtered residue was dried for $24 \mathrm{~h}$ in an oven at $105^{\circ} \mathrm{C}$. Then, the residue of each sample was weighed to calculate the ratio of the residue using Equation (1).

$$
\text { Ratio of residue }=\frac{R_{i}}{R} \times 100
$$

where $R$ is the weight ratio (\%) of the residue in the sampling vial and $R_{i}$ is the initial weight ratio (\%) of the wood powder sample in the reaction flask.

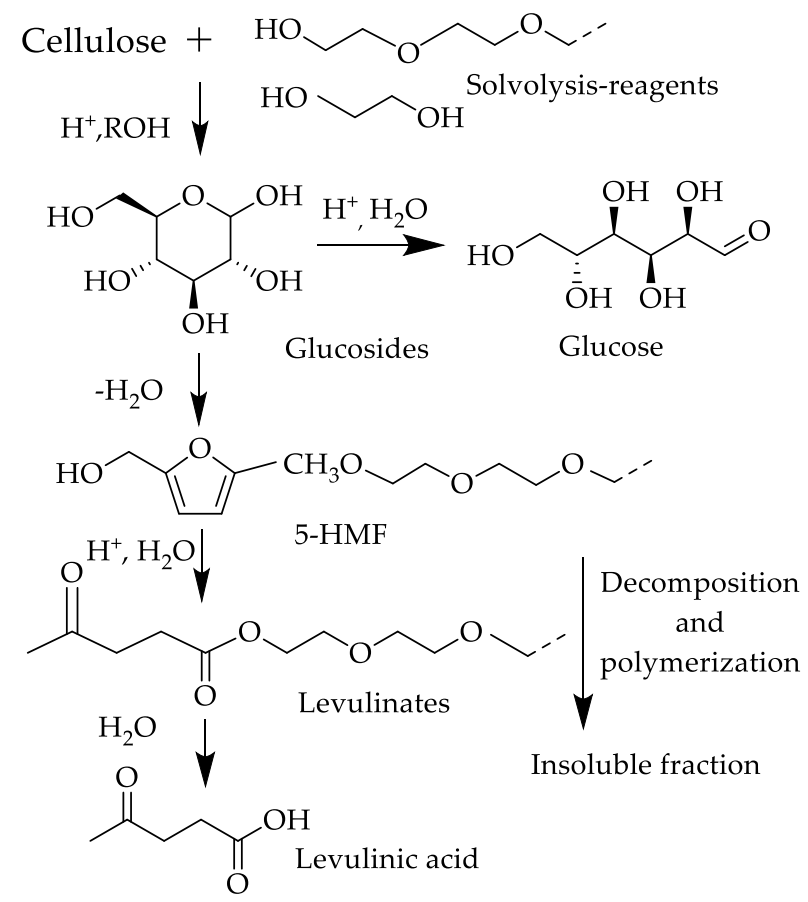

Scheme 2. Mechanism of cellulose degradation and decomposition during liquefied processes of woody materials $[24,25]$. 


\subsection{Characterization of Liquefaction Products}

The hydroxyl and acid values of liquefied wood are important factors that determine the properties of the synthetic resin. The acid number and hydroxyl number of the liquefied cotton stalk were determined as described elsewhere [5]. The amount of acid groups was estimated by $\mathrm{NaOH}$ titration using the JIS-K1557 standard method.

\subsection{Preparation of Liquefied Cotton-Stalk-Based Epoxy Resins}

Epichlorohydrin was put in a $500 \mathrm{~mL}$ three-necked flask in an amount that is 15 times the molar amount of hydroxyl groups in the liquefied cotton stalk. Liquefied cotton stalk and epichlorohydrin were placed in a three-necked flask equipped with a stirrer and a cooler, immersed in a high-temperature water tank preheated to $60^{\circ} \mathrm{C}$, and preheated for $10 \mathrm{~min}$. Tetrabutylammonium hydrogen sulfate (TBAHS) (5\% by volume of liquefied cotton stalk) and sodium hydroxide (4.5 times the molar ratio of the hydroxyl value of the liquefied cotton stalk) were slowly added to the mixture under stirring. Then, the flask was maintained at $60^{\circ} \mathrm{C}$ for $4 \mathrm{~h}$. The reaction products were diluted with acetone and salts produced as byproducts were filtered out using glass-fiber filter paper (Toyo GA-100: $1 \mu \mathrm{m}$ particle-retainable). The filtrate was transferred to an eggplant-shaped flask and distilled with a rotary evaporator under heating and reduced pressure at $80{ }^{\circ} \mathrm{C}$ to remove the unreacted epichlorohydrin with acetone to remove the liquefied epoxy resin. The mechanism is shown in Scheme 3.

$$
\begin{aligned}
& \mathrm{R}-\mathrm{OH}+\mathrm{NaOH} \rightarrow \mathrm{R}-\mathrm{O}-\mathrm{Na}+\mathrm{H}_{2} \mathrm{O} \\
& \mathrm{R}-\mathrm{O}-\mathrm{Na}+\left(\mathrm{C}_{4} \mathrm{H}_{9}\right)_{4} \mathrm{~N}^{+} \mathrm{HSO}_{4}^{-} \rightarrow\left(\mathrm{C}_{4} \mathrm{H}_{9}\right)_{4} \mathrm{~N}^{+}-\mathrm{O}-\mathrm{R}+\mathrm{Na}^{+} \mathrm{HSO}_{4}^{-} \\
& \text {TBAHS }
\end{aligned}
$$

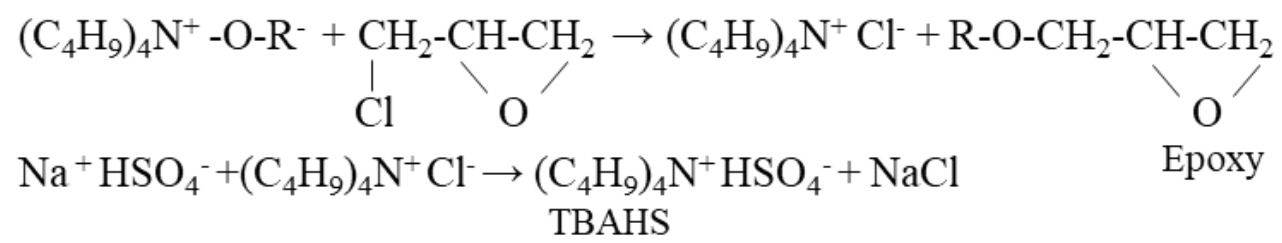

Scheme 3. Reaction routes for glycidyl etherification of alcoholic $\mathrm{OH}$ groups using $\mathrm{NaOH}$ and TBAHS.

\subsection{Fourier-Transform Infrared (FTIR) Spectroscopy}

The functional groups of the liquefied cotton stalk samples were characterized by FTIR spectroscopy (FT/IR-6100, JASCO Co. Ltd.,Tokyo, Japan) as described in a previous report [5]. The liquefied sample was simply attached to the $\mathrm{KBr}$ disc and was placed in the FTIR instrument for measurement. The infrared spectrum was recorded in the $400-4000 \mathrm{~cm}^{-1}$ range by averaging 64 scans at a resolution of $4 \mathrm{~cm}^{-1}$.

\subsection{Molecular Weight, Epoxy Equivalent Weight, and Viscosity}

The liquefied cotton stalk $(10 \mathrm{mg})$ and resin samples were diluted with $10 \mathrm{~mL}$ of tetrahydrofuran $(0.1 w / v \%)$, and the diluted samples were analyzed by gel permeation chromatography (GPC) using an HPLC pump (Pump PU-2080, JASCO Co. Ltd., Japan), refractive index detector (RI-2031, JASCO Co. Ltd., Japan) and column thermostat (CO2060, JASCO Co. Ltd., Japan). After the column temperature was stabilized over $\sim 30 \mathrm{~min}$, the pump feed rate was set to $0.5 \mathrm{~mL} / \mathrm{min}$ and the sample was injected into the injector with a syringe to begin the analysis.

The epoxy equivalent of the cotton-stalk-based resin was determined according to JIS K7236 standard. The epoxy resin (0.4-2.3 g) was dissolved in $10-15 \mathrm{~mL}$ of chloroform in a $50 \mathrm{~mL}$ flask. Then, tetraethylammonium bromide $(10 \mathrm{~mL})$ was added, and the resulting solution was mixed using a magnetic stir bar. 
The viscosities at $25 \pm 0.1^{\circ} \mathrm{C}$ were measured using a viscometer (SV-10/SV-100). The vibrating viscometer was calibrated by the tuning-fork vibration method using standard purified water before PEG 400/glycerin-based epoxy resin, the cotton-stalk-based resin, and Epon 828 were measured. For accurate measurement, the samples were allowed to stand at room temperature for $2 \mathrm{~h}$, and then $10 \mathrm{~mL}$ of it was placed in the glass sample cup (AX-SV-35). Then, the sample was left undisturbed for a certain duration after placing the sensor plates and temperature sensor to allow the sample temperature $\left(25^{\circ} \mathrm{C}\right)$ to stabilize [5].

\subsection{Preparation of Cured Resins Using the Cotton-Stalk-Based Epoxy Resins}

Four different types of cured epoxy resins were prepared using four parts of resin and one part of a hardener. The cotton-stalk-based epoxy resins were mixed mechanically at room temperature with Epon 828 at four different weight ratios of $0 \%, 10 \%, 20 \%$, and $30 \%$ to obtain cured epoxy-based polymers. All the resins mixed at four proportions were

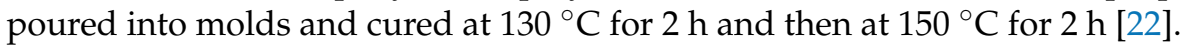

\subsection{Tensile Test}

The flexural tests of the cured resins were measured on the electronic universal testing machine at a strain rate of $5 \mathrm{~mm} / \mathrm{min}$. Test specimens with a length of $80 \mathrm{~mm}$, width of $10 \mathrm{~mm}$, and thickness of $2 \mathrm{~mm}$ were machined from $2 \mathrm{~mm}$ thick plaques of cured resins.

\subsection{DSC and TGA}

The glass transition temperature $(\mathrm{Tg})$ and thermal degradation characteristics of the cured bio-oil/epoxy resins were analyzed using a differential scanning calorimeter. We evaluated the thermal stability of the resins by DSC (DSC6200, Seiko Instruments Inc., Chiba, Japan). A 3-5 mg sample of cured epoxy resin was weighed on a balance and placed in an aluminum pan. After changing the temperature from the ambient temperature to $20{ }^{\circ} \mathrm{C}$, the temperature was raised from $25{ }^{\circ} \mathrm{C}$ to $200{ }^{\circ} \mathrm{C}$ at a heating rate of $5{ }^{\circ} \mathrm{C} / \mathrm{min}$. The analysis was performed using the analysis job Standard Analysis. For polymers, the glass transition temperature $(\mathrm{Tg})$ is defined as the temperature at which their mechanical properties change radically from the glass state to a highly elastic state owing to the internal motion of the polymer chains. The onset of the transition is considered as the $\mathrm{Tg}$.

To evaluate the thermal decomposition characteristics of the cured resins, simultaneous TG-DTA analysis was performed using a TG-DTA device (DTG-60 Shimadzu Corporation). The cured epoxy resins $(10 \mathrm{mg}$ ) were placed on the $\mathrm{Pt}$ cell in the furnace, and the gas within the device was replaced with the carrier gas (Ar) for $15 \mathrm{~min}$. The resin was heated from room temperature to $500{ }^{\circ} \mathrm{C}$ at a heating rate of $20^{\circ} \mathrm{C} / \mathrm{min}$ under an Ar flow rate of $100 \mathrm{~mL} / \mathrm{min}$. The weight loss and derivative weight loss (DTG) curves were plotted and analyzed.

\section{Results and Discussion}

\subsection{Optimization of the Cotton Stalk Liquefaction Process}

Liquefaction conditions, such as the reaction temperature, reaction time, PEG 400/glycol mass ratio, and solvent/cotton stalk mass ratio, greatly influence the properties of liquefied cotton stalk. In order to obtain high-quality biopolyols through the liquefaction of lignocellulosic biomass, polyols with appropriate molecular weight and hydroxyl number should be used as the liquefaction solvent [26]. The hydroxyl value of the liquefied biomass is an important factor in the preparation of epoxy resins. The hydroxyl and acid values of the cotton stalk were determined using the standard method of esterification with phthalic anhydride.

\subsubsection{Effects of Reaction Parameters on the Hydroxyl Value}

Under the reaction temperature $150{ }^{\circ} \mathrm{C}$, reaction time $90 \mathrm{~min}$, and PEG 400/glycol mass ratio $8 / 2$, the effects of the weight ratio of the liquefaction solvent to cotton stalk on 
the acid and hydroxyl values of biopolyols are presented in Figure 1a. The acid values of cotton-stalk-based polyols obtained using liquefaction reagent/cotton stalk weight ratios of $3 / 1$ to $6 / 1(w / w \%)$ were less than $25 \mathrm{mg} \mathrm{KOH} / \mathrm{g}$. The number of carboxylic acid groups in a chemical substance, such as a fatty acid, or in a combination of compounds is referred to as the acid value. The hydroxyl value of cotton-stalk-based polyols increased significantly from 250 to $350 \mathrm{mg} \mathrm{KOH} / \mathrm{g}$ when the weight ratio of the liquefaction solvent to cotton stalk was increased from $3 / 1$ to $5 / 1(w / w \%)$ and then marginally to $320 \mathrm{mg} \mathrm{KOH} / \mathrm{g}$ with a further increase in the weight ratio to $6 / 1(w / w \%)$. This result suggests that there was a slight in the hydroxyl value as the weight ratio was increased. The biomass content in the liquefaction solvent can substantially affect the properties of biopolyols. The main function of the liquefaction agent is to dissolve and disperse the liquefied product, inhibit the recondensation of the product, and reduce the residue rate [5]. The liquefaction agent can quickly decompose the cotton stalk so that the molecular weight of the liquefied product is rapidly reduced and stabilized. At the same time, it plays an important role in inhibiting the recondensation of the intermediate product obtained from the decomposition of the cotton stalk component.
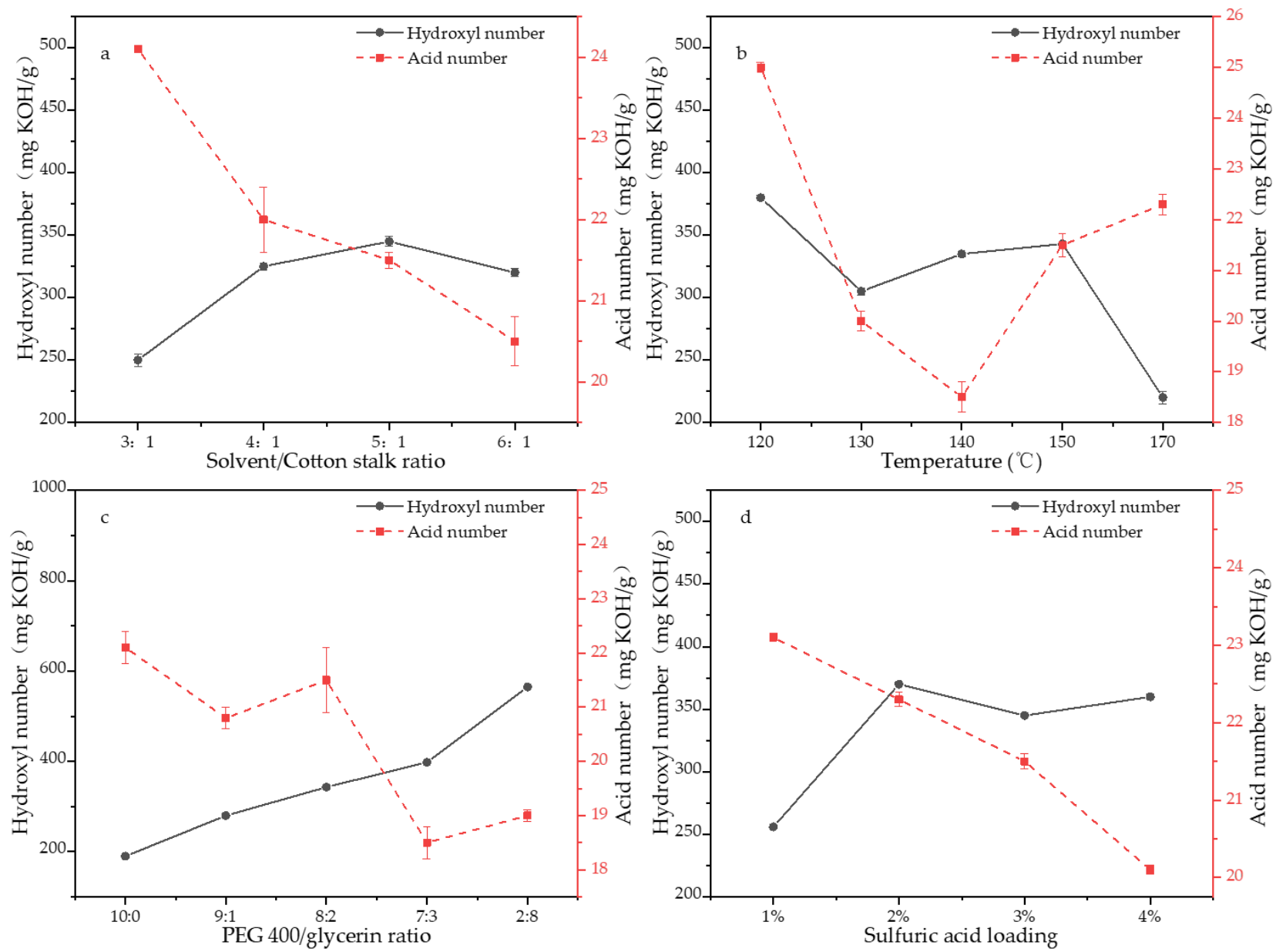

Figure 1. Effects of liquefaction conditions on the acidity and hydroxyl number of biopolyols: (a) Solvent/Cotton stalk ratio, (b) temperature, (c) PEG 400/glycerin ratio, and (d) catalyst (sulfuric acid) content.

PEG 400/glycol mass ratio 8/2, reaction time 90 min, liquefaction solvent to cotton stalk ration $5 / 1$, and the amount of concentrated sulfuric acid of the catalyst is $3 \%$ of the mass of the liquefaction agent. The effect of liquefaction temperature on the liquefaction effect and the hydroxyl value of the liquefied product is investigated. The results are shown in Figure 1b. The residue content of liquefied cotton stalk decreased from 30.0 to 13.5\%. The greater the liquefaction reaction temperature, the higher the liquefaction efficiency. The 
hydroxyl number increased from 280.6 to $360.2 \mathrm{mg} \mathrm{KOH} / \mathrm{g}$ with an increase in the reaction temperature from 120 to $130^{\circ} \mathrm{C}$. When the reaction temperature is increased to $150{ }^{\circ} \mathrm{C}$, there is lower residue, and the hydroxyl value of the liquefied product can reach $343 \mathrm{mgKOH} / \mathrm{g}$. When the reaction temperature was further increased to $160{ }^{\circ} \mathrm{C}$, the residue rate did not change much, but too high temperature caused side reactions such as condensation and pyrolysis between the liquefied products, resulting in a decrease in the hydroxyl value of the liquefied products. A further increase in temperature leads to an obvious increase in the residue content and a decrease in the hydroxyl number, indicating that the recondensation of the products occurred during the liquefaction process when the temperature was higher than $160^{\circ} \mathrm{C}$. Higher temperatures are favorable for the degradation of lignin, cellulose, and hemicellulose. However, as the temperature increases, the degree of degradation increases, and the recondensation of the degradation fragments is promoted. A similar phenomenon was also observed by Liu [11].

PEG 400 and glycerin were used as the liquefaction solvent at different ratios, the solvent/cotton stalk ratio was $5 / 1(w / w \%)$, and the catalyst concentration was $3 \%(w / w \%)$ and reacted at $150{ }^{\circ} \mathrm{C}$ for $90 \mathrm{~min}$. Figure $1 \mathrm{c}$ shows the effect of the PEG $400 /$ glycerin mass ratio on the properties of the liquefied product. The lowest hydroxyl number and highest residue content were obtained when PEG 400 only (without glycerin) was used as the liquefaction reagent. Among the liquefiers, the residue rate is the lowest when the PEG400:glycerol mass ratio is 8:2, but the hydroxyl value is the highest when the ratio is 2:8. This is mainly because the liquefaction effect of PEG400 is better, and the liquefaction effect of glycerol is poor, so when the amount of glycerin is too much, the liquefaction effect becomes worse, but the addition of glycerol is conducive to the dissolution of cotton stalk macromolecules and the formation of small molecular hydroxyl compounds. Glycerin is an excellent proton donor, and it can effectively capture the free radicals produced in the lignin degradation process. Consequently, it can inhibit the recondensation, facilitate $\mathrm{CO}_{2}$ release and the production of ethylene glycol, and thus promote the liquefaction of the biomass [16]. Therefore, glycerin was used as the auxiliary liquefaction solvent in this study. A comprehensive comparison shows that the quality ratio of PEG 400/glycerin mass ratio in the liquefaction agent is $8 / 2$.

The liquefaction of biomass needs to be catalyzed by acid or alkali, and the main components such as lignin and cellulose are carried out through a series of hydrolysis and solvolysis reactions. The decomposition of lignocellulosic biomass during liquefaction proceeds mainly via a series of hydrolysis and solvolysis reactions, which can be catalyzed by acids or bases. Wang and Chen [20] compared the catalytic effects of different acids such as hydrochloric acid, phosphoric acid, and sulfuric acid in the liquefaction of wheat straw and found that sulfuric acid exhibits the best catalytic activity, leading to minimum residual biomass content $[26,27]$. The effects of sulfuric acid concentration on the acid and hydroxyl numbers of the biopolyols are given in Figure 1d. The acid number of the biopolyols was less than $25 \mathrm{mg} \mathrm{KOH} / \mathrm{g}$ at all acid concentrations ranging from 2 to $4 \%$. Concentrations ranging from 1 to $3 \%$, with the increase in the amount of catalyst, the hydroxyl value of the liquefied cotton stalk is gradually increased. When the amount of concentrated sulfuric acid is $3 \%$ of the mass of the liquefaction agent, the hydroxyl value reaches the maximum value. When the amount is greater than $3 \%$, the residue rate will not decrease much, mainly because the condensation reaction between the liquefied products occurs under the action of concentrated sulfuric acid. In addition, when the amount of sulfuric acid is too much, side reactions such as oxidation and condensation will occur, causing carboxyl groups in the system and condensation reaction with the hydroxyl groups of the liquefaction agent, resulting in a decrease in liquefaction efficiency. Therefore, the amount of concentrated sulfuric acid used in the catalyst is $3 \%$ of the quality of the liquefaction agent.

In summary, the effect of different variables on the hydroxyl value of the liquefaction product is comparable with that of other biomass raw materials on polyol liquefaction. The optimal liquefaction process for cotton stalk is one in which the mass ratio of cotton stalk to liquefaction agent is $1: 5$, the concentration of concentrated sulfuric acid in the catalyst is 
$3 \%$ of the mass of the liquefaction agent, the PEG/glycerol ratio is $8: 2$ ( $w / w$ percent), the reaction time is $90 \mathrm{~min}$, and the temperature is $150{ }^{\circ} \mathrm{C}$.

\subsubsection{Effects of Reaction Parameters on the Residue Content}

In our previous study [5], we investigated the optimal liquefaction conditions for the liquefaction of cotton stalk by evaluating the residue rate. In the study, to achieve high liquefaction efficiency and minimize recondensation reactions, the liquefaction of cotton stalk was performed using a solvent/biomass ratio of $5 / 1$, the sulfuric acid concentration of $3 \%$, and temperature of $150{ }^{\circ} \mathrm{C}$. However, the effects of different PEG 400/glycerin mixed solvents on liquefaction were not evaluated in our previous study. In this study, we investigated the effect of using a PEG 400/glycerin blended solvent at different ratios on the liquefaction of cotton stalks at $90 \mathrm{~min}$ of reaction time; the results are indicated in Table 1. It is evident from the data that, upon mixing $10 \%$ glycerin with PEG 400, the amount of residue decreased from 30.2 to $13.4 \%$ for the cotton stalk. However, the addition of greater than $20 \%$ glycerin to PEG 400 was not beneficial, as the residue content increased slightly in the case of cotton stalk. Based on the results, it can be concluded that the addition of $20 \%$ glycerin to PEG 400 is very effective for decreasing the amount of residue or increasing the liquefaction yield. To obtain polyols from different biomass feedstocks, binary solvent mixtures such as polyhydric alcohols of different ratios are generally used. For example, a PEG/glycerol ratio of 4:1 (w/w\%) was used for processing rapeseed, date seed, olive stone, corncob, and apple pomace, while 9:1 $(w / w \%)$ was used for processing wood species and bagasse and in the enzymatic hydrolysis of lignin [28,29].

Table 1. Effect of reaction conditions on the minimal residue.

\begin{tabular}{cccc}
\hline Parameter & Numerical Value & Minimal Residue (\%) & Reference \\
\hline \multirow{2}{*}{ Temperature $\left({ }^{\circ} \mathrm{C}\right)$} & 130 & 30.0 & \\
& 140 & 20.2 & \\
Catalyst content $(\%)$ & 150 & 13.5 & \\
& 160 & 16.6 & Wang et al. (2020) \\
& 1 & 22.4 & \\
Solvent/cotton stalk & 2 & 20.0 & \\
$(w / w \%)$ & 4 & 13.2 & \\
& 3 & 12.5 & \\
※ PEG $400 /$ Glycerin & 5 & 32.4 & This study \\
$(w / w \%)$ & 6 & 28.3 & \\
\hline
\end{tabular}

※ Liquefaction temperature, $150^{\circ} \mathrm{C}$; liquefaction time, $90 \mathrm{~min}$; Sulfuric acid $3 \%$; Solvent/cotton stalk, 5/1.

3.1.3. Structural Characteristics of the Liquefied Cotton Stalk and Liquefied Cotton-Stalk-Based Epoxy Resin

The FTIR absorption spectra of pure PEG 400/glycerin-based epoxy resin, liquefied cotton stalk, liquefied cotton-stalk-based epoxy resin, and Epon 828 are presented in Figure 2. The liquefied cotton stalk polyol, liquefied cotton-stalk-based epoxy resin, and pure PEG 400/glycerin-based epoxy resin samples exhibited broad peaks in the range of 3200 to $3600 \mathrm{~cm}^{-1}$, corresponding to the vibrations of aromatic and aliphatic - $\mathrm{OH}$ groups of the PEG/glycerin polyol [30]. The characteristic absorption bands of the liquefied cotton stalk appeared at $2909 \mathrm{~cm}^{-1}\left(-\mathrm{CH}_{2}\right.$ asymmetric), 1640 and $1426 \mathrm{~cm}^{-1}(\mathrm{C}=\mathrm{C}$ aromatic rings generated by lignin decomposition), $1097 \mathrm{~cm}^{-1}$ (C-O stretch in hemicellulose), and $1107 \mathrm{~cm}^{-1}$ (C-H stretch in cellulose). After the liquefied cotton stalk was reacted with epichlorohydrin to form the liquefied cotton-stalk-based epoxy resin, epoxy functional- 
ization was confirmed by the peaks in the range of $906-911 \mathrm{~cm}^{-1}$ (due to the asymmetric bending of the epoxide ring). The peaks observed in the range of $835-845 \mathrm{~cm}^{-1}$ are due to the symmetric bending of the epoxide ring, indicating the presence of the epoxide functional group. Compared with the spectrum of the liquefied cotton stalk polyol, the significant difference observed in the spectra of the epoxy resin samples (liquefied cottonstalk-based epoxy resin, pure PEG 400/glycerin-based epoxy resin, and Epon 828) was the lower -OH stretching band intensity. This is due to the conversion of phenolic hydroxyl and carboxyl hydroxyl groups to glycidyl functionality. The peak of the aliphatic hydroxyl groups, however, tends to appear owing to their low reactivity during epoxidation. The absorption bands at $1330 \mathrm{~cm}^{-1}$ are attributed to in-plane bending vibrations of $-\mathrm{CH}_{2}$. For epoxy as well as the liquefied cotton-stalk-based epoxy resin sample, and the characteristic stretching vibration bands of the epoxy linkage, CO-C appeared at $910 \mathrm{~cm}^{-1}$. These peaks are considered important for resinification; hence, their intensities were compared [19]. The results suggest that the cotton stalk was introduced into the molecular structure of the epoxy resins.

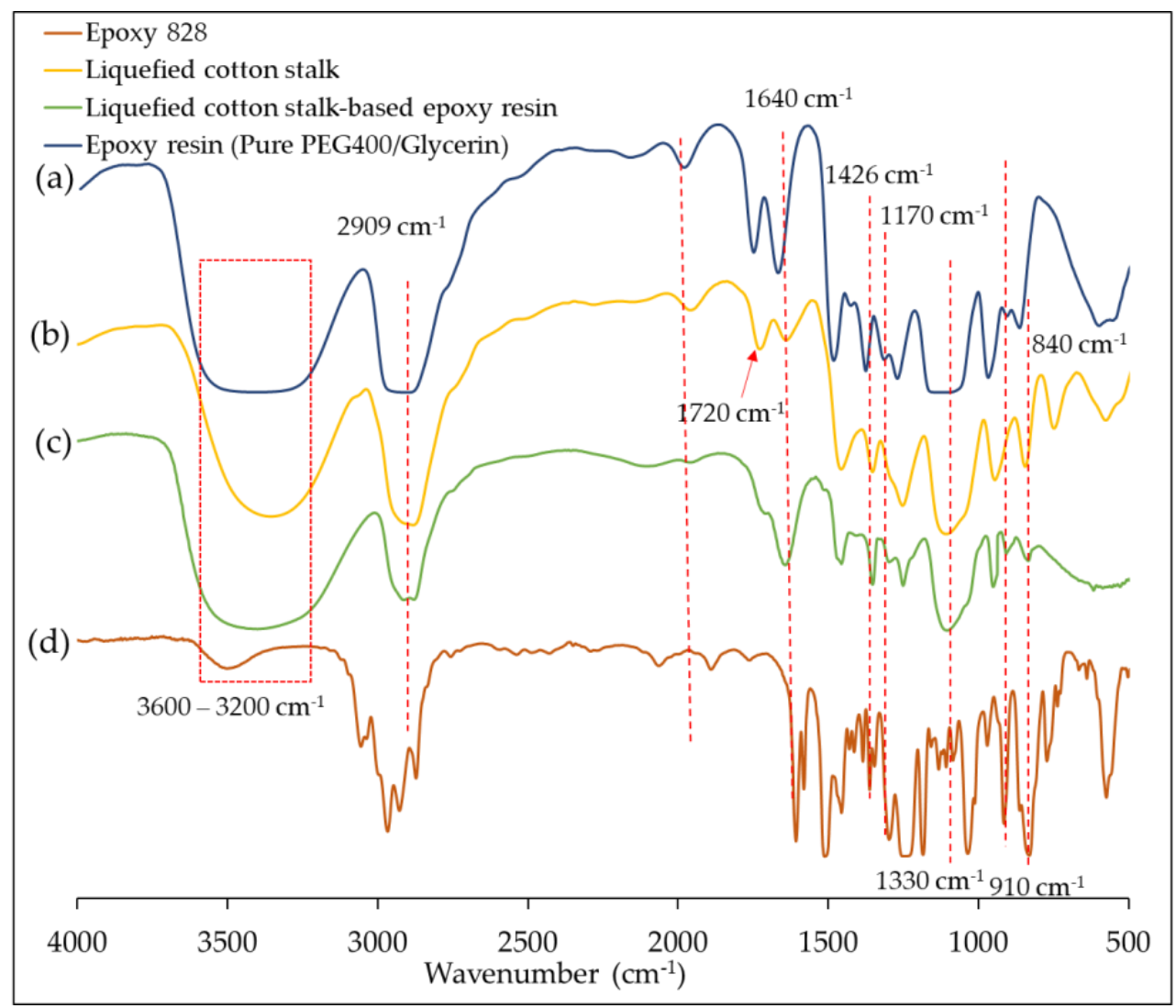

Figure 2. FTIR spectra of (a) pure PEG 400/glycerin-based epoxy resin, (b) liquefied cotton stalk, (c) liquefied cotton-stalk-based epoxy resin, and (d) commercial epoxy resin.

\subsection{Properties of the Liquefied Cotton-Stalk-Based Epoxy Resin}

The properties of three epoxy resins, viz., the PEG 400/glycerin-liquefied cotton-stalkbased epoxy resin (LCS- based epoxy resin), PEG 400/glycerin epoxy resin, and Epon 828, are compared in Table 2. The viscosities of the three epoxy resins were measured using a viscometer at $25^{\circ} \mathrm{C}$. The viscosity of LCS- based epoxy resin was determined to be $1020 \mathrm{~m} \mathrm{~Pa} \cdot \mathrm{s}$, which was higher than the viscosity of the PEG 400/glycerin-based epoxy resin and Epon 828. Data presented in a previous investigation [4] using the various rates of wood material indicated that increased wood content resulted in a markedly higher viscosity of liquefied woods. The reason is the increase in the number of liquefied woods fragments having partially degraded wood components. Their molecular weights were 
determined using GPC. The cotton-stalk-based resin had an average molecular weight of $726 \mathrm{Da}$, whereas the PEG 400/glycerin-based epoxy resin and Epon 828 had average molecular weights of 690 and $370 \mathrm{Da}$, respectively. In comparison to the PEG 400/glycerinbased epoxy resin, the cotton-stalk-based resin had a reduced molecular weight, suggesting that the cured resin would function more uniformly. The epoxy equivalent of the cottonstalk-based resin was determined to be $250 \mathrm{~g} / \mathrm{eq}$ using a titration technique based on the hydroxyl value of liquefied cotton stalk and the epoxy equivalent of liquefied cottonstalk-based epoxy resins. The epoxy equivalent of the relevant PEG 400/glycerin-based epoxy resin was determined to be $440 \mathrm{~g} / \mathrm{eq}$, which was considerably more than the epoxy equivalent of the LCS-based epoxy resin. The findings above show that the molecules derived from liquid cotton stalks were chemically united in the produced epoxy resin.

Table 2. Properties of liquefied cotton stalk-based epoxy resins.

\begin{tabular}{ccccccc}
\hline \multirow{2}{*}{ Epoxy Resin } & \multicolumn{2}{c}{ Properties of Liquefied Cotton Stalk } & \multicolumn{3}{c}{ Properties of Epoxy Resins } \\
\cline { 2 - 6 } & $\begin{array}{c}\text { PEG } \\
\text { 400/glycerin }\end{array}$ & $\begin{array}{c}\text { Hydroxyl Value } \\
\text { (mg KOH/g) }\end{array}$ & $\begin{array}{c}\text { Viscosity } \\
\text { (m Pa·s) }\end{array}$ & $\begin{array}{c}\text { Epoxy Equivalent } \\
\text { Weight (g/eq) }\end{array}$ & $\begin{array}{c}\text { Molecular } \\
\text { Weight }\end{array}$ & $\begin{array}{c}\text { Viscosity } \\
(\mathbf{m} \text { Pa·s) }\end{array}$ \\
\hline LCS-based epoxy resin & $8 / 2$ & 343 & 1020 & 250 & 726 & 540 \\
\hline $\begin{array}{c}\text { PEG 400/glycerin-based } \\
\text { epoxy resin }\end{array}$ & $8 / 2$ & 321 & 320 & 440 & 690 \\
\hline Epon 828 & - & - & - & 190 & 370 \\
\hline
\end{tabular}

Liquid ratio, 5:1; acid content, $3 \%$; temperature, $150^{\circ} \mathrm{C}$. Syntheses were conducted for $6 \mathrm{~h}$ at $4.2 \mathrm{NaOH} / \mathrm{hydroxyl}$ value ratios at $60{ }^{\circ} \mathrm{C}$. Cured with the PAA hardener, at $130^{\circ} \mathrm{C}$ for $2 \mathrm{~h}$ and then at $150{ }^{\circ} \mathrm{C}$ for $2 \mathrm{~h}$.

\subsection{Properties of the Cured Liquefied Cotton-Stalk-Based Epoxy Resin}

As for their poor mechanical properties, the main defect of bio-based epoxy resins is that they cannot take the place of petroleum-based epoxy resins, for example, Epon 828 . In the present work, cured epoxy was prepared at a resin/hardener ratio of $4 / 1$. The resin/PAA hardener mixture was cured at $130{ }^{\circ} \mathrm{C}$ for $2 \mathrm{~h}$ and then at $150{ }^{\circ} \mathrm{C}$ for $2 \mathrm{~h}$. The hardener, PAA, is an aromatic curing agent that imparts samples with low viscosity and high strength. Figure 3 compares the room-temperature flexural properties of the cured liquefied cotton-stalk-based epoxy resin with those of the Epon 828-type resin. The blends of cotton-stalk-based epoxy resins and the commercial epoxy resin were prepared at three different cotton-stalk-based epoxy resin weight percentages of 10, 20, and 30\%. The tensile properties of the cured bio-epoxy resin with $20 \%$ cotton-stalk-based epoxy component were comparable to those of commercial products. The cured cotton-stalk-based epoxy resin exhibited a higher flexural modulus than that of Epon 828. Moreover, the tensile strength of the liquefied cotton-stalk-based epoxy resins (35.4 MPa) is higher than both liquefied wood-based epoxy (34 MPa) [23] and epoxidized soybean oil-based epoxy (29 MPa). The usage of the bio-based epoxy resin as a substitute is because of their worthy property, namely high stiffness. Compared to epoxidized soybean oil with a long-chain structure, liquefied bio-based epoxy has better application prospects in the automobile and aerospace industries [24].

\subsection{Thermal Stability of the Epoxy Resins}

In this study, DSC heat scanning was conducted to investigate the curing behaviors of copolymer epoxy resins for a comprehensive understanding of the thermal properties of these resins. Figure 4 shows the variation in the heat flow of various resins during the DSC heat scans. All resins exhibited an exothermic peak. The intensity of the exothermic peak decreased with an increasing amount of the liquefied cotton-stalk-based resin in the composite, indicating that fewer crosslinking reactions occurred during the curing period. In particular, when $30 \%$ of Epon 828 was replaced with the liquefied cotton-stalk-based resin, the resulting resin exhibited higher peak temperatures and released less heat during the curing reaction, indicating lower reactivity. Similar findings were made by $\mathrm{Wu}$ and 
Chen [31], who combined liquefied wood and epoxy resin in different weight ratios and discovered that increasing the quantity of liquefied wood in the mixture shifted the peak of the curing reaction to a higher temperature but with less heat produced. As discussed earlier, the epoxy resins copolymerized with liquefied cotton-stalk-based resin had a higher epoxide equivalent weight (EEW), implying that they had less content of epoxy groups per unit weight of the resin, possibly resulting in lesser crosslinking reactions. Furthermore, the long molecular chain of polyethylene glycol present in polyhydric alcohol-liquefied cotton stalk would also decrease the reactivity of these liquefied bio-based epoxy resins, leading to higher onset and peak temperatures of the curing reaction.



Figure 3. Tensile strength and modulus of the cured epoxy resins (LCS: liquefied cotton stalk).



Figure 4. DSC curves of Epon 828 and Epon 828/cotton stalk-based-epoxy resin blends were obtained at the heating rate of $10^{\circ} \mathrm{C} / \mathrm{min}$.

\subsection{Thermal Properties of Cured Liquefied Cotton-Stalk-Based Epoxy Resins}

Thermal behavior is a very important property because epoxy resins are one of the most popular classes of functional polymers in many applications. Many studies [4,32] have been conducted to enhance the thermal properties of epoxy resins. For instance, Fujiwara et al. [15] prepared epoxy resins containing different amounts of wood-based samples and found that the thermal stability decreased with an increase in the amount of 
the wood-based samples. They attributed the results to the number of the material derived from wood, which is more prone to thermal decomposition. Cellulose, hemicellulose, and lignin, which are major components of its composition, decompose over temperatures from 160 to $450{ }^{\circ} \mathrm{C}$ [22].

In this article, the evaluation of the thermal properties of the resins was performed using a TG-DTA system. The TGA curves of the liquefied cotton-stalk-based epoxy resin (Figure 5) revealed three stages of thermal degradation of Epon 828, and the maximum weight loss of $\sim 90 \%$ occurred in the temperature from 270 to $400{ }^{\circ} \mathrm{C}$. Meanwhile, the TGA curve exhibits four stages of degradation for the liquefied cotton-stalk-based resin/Epon 828 blend. The first step between room temperature and $120{ }^{\circ} \mathrm{C}$ is attributed to the dehydration of the sample [33]. The weight loss was approximately $3-5 \%$ during this dehydration stage and nearly two times as much, $9 \%$, in the second stage between 120 and $230{ }^{\circ} \mathrm{C}$. The weight loss reached $65 \%$ at $500{ }^{\circ} \mathrm{C}$. When the temperature was beyond $500{ }^{\circ} \mathrm{C}$, a negligible loss of $5 \%$ occurred. For the epoxy 828 , the highest rate of decomposition was $320^{\circ} \mathrm{C}$, which was attributed to the breakdown of epoxy groups. Liu [13] found the clean epoxy to have the highest degradation at a higher temperature of $358{ }^{\circ} \mathrm{C}$, which is also comparable with the ones reported in this study.

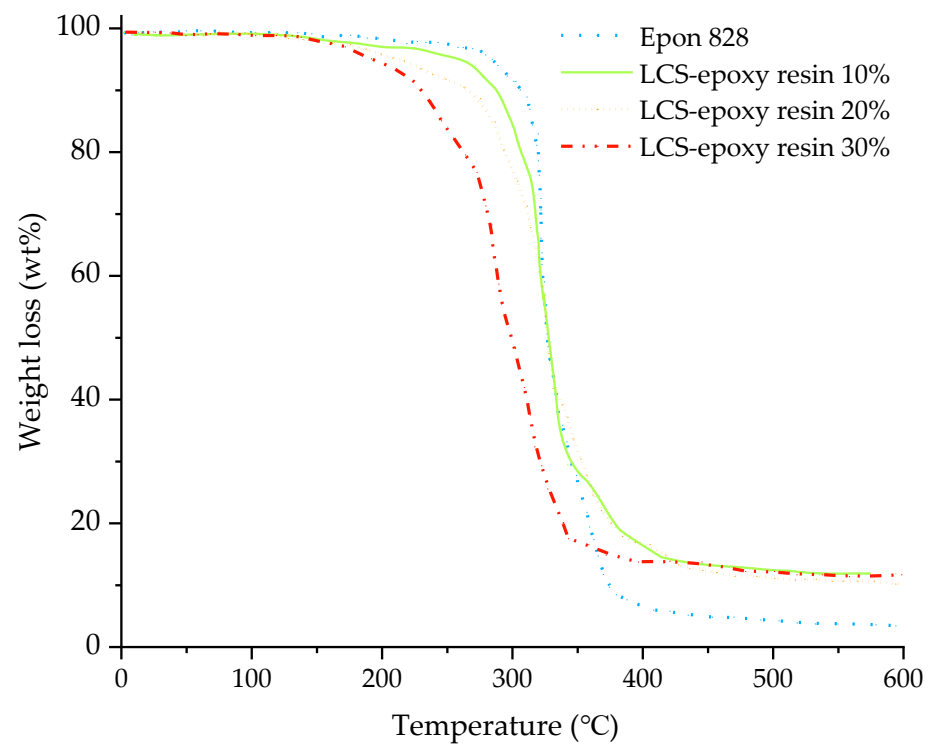

Figure 5. Thermogravimetric curves of the cured epoxy resins.

\section{Conclusions}

Liquefied cotton-stalk-based epoxy resin, a new bio-based epoxy resin, was prepared from liquefied cotton stalk and epichlorohydrin according to known glycosylation procedures. In addition, the liquefied cotton-stalk-based epoxy resin was blended with Epon 828 epoxy resin in different proportions (i.e., 10, 20, and 30 mass \%) and cured with methylhexahydrophthalic anhydride as the curing agent in the presence of 2-methylimidazole as the catalyst. A tensile strength study showed that the cotton-stalk-based epoxy resinmodified Epon 828 mix improved its tensile strength from 15.2 to $35.4 \mathrm{MPa}$. When added at a concentration of $20 \%$, the cotton stalk epoxy resin significantly enhanced the durability of the Epon 828 epoxy network. Additionally, DSC was used to examine the curing behaviors of Epon 828 and its bio-based mix systems, while TGA was used to determine their thermal stability. With the addition of the cotton-stalk-based epoxy resin, a rise in the peak temperature and a decrease in the heat of curing and activation energy of Epon 828 were detected. TGA analysis revealed that the rate of the decomposition of the bio-based epoxy blend system was marginally higher than that of Epon 828 and occurred at a lower temperature. The optimal liquefaction process for cotton stalk is one in which the mass ratio of cotton stalk to liquefaction agent is 1:5, the concentration of concentrated sulfuric acid in the catalyst is $3 \%$ of the mass of the liquefaction agent, the PEG/glycerol ratio is 
$8: 2\left(w / w\right.$ percent), the reaction time is $90 \mathrm{~min}$, and the temperature is $150{ }^{\circ} \mathrm{C}$. This study demonstrates the possibility of using polyols derived from liquefied cotton stalk to produce epoxy resins. For future work, to better understand the liquefaction properties and resin properties from biomass, we should investigate various types of agricultural residue. In addition, it is necessary to research the biodegradability of the new cotton stalk-based epoxy resin. Producing high-value bio-products by using agricultural residues contributes to establishing a sustainable economy and at the same time has an essential positive effect on the environment.

Author Contributions: Conceptualization, N.T. and Q.W.; methodology, N.T.; software, N.T.; validation, N.T.; formal analysis, N.T. and Q.W.; investigation, N.T.; resources, Q.W.; data curation, N.T. and Q.W.; writing—original draft preparation, N.T.; writing—review and editing, N.T. and Q.W.; visualization, N.T.; supervision, N.T. and Q.W.; project administration, Q.W.; funding acquisition, Q.W. Both authors have read and agreed to the published version of the manuscript.

Funding: This study was partially supported by the Special Funds for Innovative Area Research (No. 20120015, FY 2008-FY2012) and Basic Research (B) (No. 24310005, FY2012-FY2014; No. 18H03384, FY2017-FY2020) of Grant-in-Aid for Scientific Research of the Japanese Ministry of Education, Culture, Sports, Science and Technology (MEXT) and the Steel Foundation for Environmental Protection Technology of Japan (No. C-33, FY 2015-FY 2017).

Institutional Review Board Statement: Not applicable.

Informed Consent Statement: Not applicable.

Data Availability Statement: The data presented in this study are available on request from the corresponding author. The data are not publicly available since these data are published for the first time. The authors have no problems providing them on request.

Acknowledgments: Parts of this study were supported. N.T. thanks the Japan Student Services Organization for a grant that enabled the completion of this study.

Conflicts of Interest: The authors declare that they have no conflict of interest.

\section{References}

1. Pan, H. Wood Liquefaction in the Presence of Phenol with a Weak Acid Catalyst and Its Potential for Novolac Type Wood Adhesives. Ph.D. Thesis, Louisiana State University and Agricultural and Mechanical College, Baton Rouge, LA, USA, 2007; p. 525.

2. Ramon, E.; Sguazzo, C.; Moreira, P.M.G.P. A review of recent research on bio-based epoxy systems for engineering applications and potentialities in the aviation sector. Aerospace 2018, 5, 110. [CrossRef]

3. Jiang, W.; Kumar, A.; Adamopoulos, S. Liquefaction of lignocellulosic materials and its applications in wood adhesives-A review. Ind. Crops Prod. 2018, 124, 325-342. [CrossRef]

4. Rastegarfar, N.; Behrooz, R.; Auad, M.L. Characterization of polyurethane foams prepared from liquefied sawdust by crude glycerol and polyethylene glycol. J. Polym. Res. 2018, 25. [CrossRef]

5. Kishi, H.; Fujita, A.; Miyazaki, H.; Matsuda, S.; Murakami, A. Synthesis of wood-based epoxy resins and their mechanical and adhesive properties. J. Appl. Polym. Sci. 2006, 102, 2285-2292. [CrossRef]

6. Wang, Q.; Tuohedi, N. Polyurethane foams and bio-polyols from liquefied cotton stalk agricultural waste. Sustainability 2020, 12, 4214. [CrossRef]

7. Hernandez, E.D.; Bassett, A.W.; Sadler, J.M.; La Scala, J.J.; Stanzione, J.F. Synthesis and Characterization of Bio-based Epoxy Resins Derived from Vanillyl Alcohol. ACS Sustain. Chem. Eng. 2016, 4, 4328-4339. [CrossRef]

8. Rao, B.S.; Palanisamy, A. Synthesis of bio based low temperature curable liquid epoxy, benzoxazine monomer system from cardanol: Thermal and viscoelastic properties. Eur. Polym. J. 2013, 49, 2365-2376. [CrossRef]

9. Wang, Q.; Chen, Q.; Mitsumura, N.; Animesh, S. Behavior of cellulose liquefaction after pretreatment using ionic liquids with water mixtures. J. Appl. Polym. Sci. 2014, 131, 40255. [CrossRef]

10. Hu, S.; Wan, C.; Li, Y. Production and characterization of biopolyols and polyurethane foams from crude glycerol based liquefaction of soybean straw. Bioresour. Technol. 2012, 103, 227-233. [CrossRef]

11. Lu, X.; Wang, Y.; Zhang, Y.; Cheng, X.; Yu, Y.; Jin, Y. Preparation of bio-polyols by liquefaction of hardwood residue and their application in the modification of polyurethane foams. J. Wuhan Univ. Technol. Mater. Sci. Ed. 2016, 31, 918-924. [CrossRef]

12. Kuo, P.Y.; De Assis Barros, L.; Sain, M.; Tjong, J.S.Y.; Yan, N. Effects of Reaction Parameters on the Glycidyl Etherification of Bark Extractives during Bioepoxy Resin Synthesis. ACS Sustain. Chem. Eng. 2016, 4, 1016-1024. [CrossRef] 
13. Li, H.; Feng, S.; Yuan, Z.; Wei, Q.; Xu, C.C. Highly efficient liquefaction of wheat straw for the production of bio-polyols and bio-based polyurethane foams. Ind. Crop. Prod. 2017, 109, 426-433. [CrossRef]

14. Liu, Y.; Via, B.K.; Pan, Y.; Cheng, Q.; Guo, H.; Auad, M.L.; Taylor, S. Preparation and characterization of epoxy resin cross-linked with high wood pyrolysis bio-oil substitution by acetone pretreatment. Polymers 2017, 9, 106. [CrossRef] [PubMed]

15. Dísouza, J.; Wong, S.Z.; Camargo, R.; Yan, N. Solvolytic Liquefaction of Bark: Understanding the Role of Polyhydric Alcohols and Organic Solvents on Polyol Characteristics. ACS Sustain. Chem. Eng. 2016, 4, 851-861. [CrossRef]

16. Kishi, H.; Fujita, A. Wood-based epoxy resins and the ramie fiber reinforced composites. Environ. Eng. Manag. J. 2008, 7, 517-523. [CrossRef]

17. Daneshvar, S.; Behrooz, R.; Najafi, S.K.; Mir, G.; Sadeghi, M. Characterization of Polyurethane Wood Adhesive Prepared from Liquefied Sawdust by Ethylene Carbonate. BioResources 2019, 14, 796-815.

18. Li, Y.; Yang, L.; Zhang, H.; Tang, Z. Synthesis and curing performance of a novel bio-based epoxy monomer from soybean oil. Eur. J. Lipid Sci. Technol. 2017, 119, 1600429. [CrossRef]

19. Lee, H.; Neville, K.; Henry, L.; Neville, K. Handbook of Epoxy Resins, 2nd ed.McGraw-Hill: New York, NY, USA, 1982.

20. Li, R.; Li, W.; Zheng, F.; Zhang, Y.; Hu, J. Versatile bio-based epoxy resin: From banana waste to applied materials. J. Appl. Polym. Sci. 2019, 136, 1-8. [CrossRef]

21. Weng, Z.; Li, J.; Qi, Y.; Wang, J.; Zhang, S.; Jian, X. Progress on High Performance and Functionalization of Bio-Based Epoxy Resins. Mater. China 2019, 38, 999-1008.

22. Cela-Dablanca, R.; Nebot, C.; Rodríguez López, L.; Fernández-Calviño, D.; Arias-Estévez, M.; Núñez-Delgado, A.; FernándezSanjurjo, M.J.; Álvarez-Rodríguez, E. Efficacy of Different Waste and By-Products from Forest and Food Industries in the Removal/Retention of the Antibiotic Cefuroxime. Processes 2021, 9, 1151. [CrossRef]

23. Wang, Q.; Kawamura, S. Decayed woody material from mushroom cultivation: Characterization of liquefaction. WIT Trans. Ecol. Environ. 2018, 217, 481-492.

24. Yamada, T.; Aratani, M.; Kubo, S.; Ono, H. Chemical analysis of the product in acid-catalyzed solvolysis of cellulose using polyethylene glycol and ethylene carbonate. J. Wood Sci. 2007, 53, 487-493. [CrossRef]

25. Guo, K.; Guan, Q.; Xu, J.; Tan, W. Mechanism of Preparation of Platform Compounds from Lignocellulosic Biomass Liquefaction Catalyzed by Bronsted Acid: A Review. J. Bioresour. Bioprod. 2019, 4, 202-213.

26. Yao, Y.; Yoshioka, M.; Shiraishi, N. Water-absorbing polyurethane foams from liquefied starch. J. Appl. Polym. Sci. 1996, 60, 1939-1949. [CrossRef]

27. Hassan, E.; Barbary, M.; Shukry, N. Polyhydric alcohol liquefaction of some lignocellulosic agricultural residues. Ind. Crop. Prod. 2008, 27, 33-38. [CrossRef]

28. Cinelli, P.; Chiellini, E.; Imam, S.H. Hybrid composite based on poly (vinyl alcohol) and fillers from renewable resources. J. Appl. Polym. Sci. 2008, 109, 1684-1691. [CrossRef]

29. Li, L.; Wang, M.; Feng, Q.; Wei, N.; Li, S.; Zhang, W.; Yang, K.; Zhang, Y. Investigation of the Relationship Between Reed Liquefaction Behavior and Thermodynamic Properties of Epoxy Resin Based on Liquefied Reed. Waste Biomass Valorization 2017, 8, 1285-1294. [CrossRef]

30. D'Souza, J.; Yan, N. Producing bark-based polyols through liquefaction: Effect of liquefaction temperature. ACS Sustain. Chem. Eng. 2013, 1, 534-540. [CrossRef]

31. Wu, C.C.; Lee, W.J. Curing behavior and adhesion properties of epoxy resin blended with polyhydric alcohol-liquefied Cryptomeria japonica wood. Wood Sci. Technol. 2011, 45, 559-571. [CrossRef]

32. Chen, J.; Wu, G.; Huo, S.; Kong, Z. Synthesis and Characterization of Curing Reaction of Epoxy Resin Obtained from Anacardic Acids. Chem. Ind. For. Prod. 2020, 40, 41-46.

33. Benyahya, S.; Aouf, C.; Caillol, S.; Boutevin, B.; Pascault, J.P.; Fulcrand, H. Functionalized green tea tannins as phenolic prepolymers for bio-based epoxy resins. Ind. Crop. Prod. 2014, 53, 296-307. [CrossRef] 